\title{
Does the Radiotherapy Technique Have an Impact on the Survival of Patients with Cervical Cancer?
}

\author{
Beyza ŞíRin ÖZDEMiR, ${ }^{1}$ Gamze Melek AKSU, ${ }^{1}$ Aylin Fidan KORCUM, ${ }^{1}$ Taylan BÜKÜLMEZ, ${ }^{2}$ \\ Mine GENÇ, ${ }^{1}$ Melek Nur YAVUZ1 \\ 'Department of Radiation Oncology, Akdeniz University, Antalya-Turkey \\ ${ }^{2}$ Department of Radiation Oncology, Van Regional Training and Research Hospital, Van-Turkey
}

\begin{abstract}
OBJECTIVE
Concurrent chemoradiotherapy is the primary treatment for patients with locally advanced cervical cancer. We evaluated the treatment results and prognostic factors in patients treated with chemoradiation.
\end{abstract}

\section{METHODS}

We retrospectively reviewed the records of 150 patients with locally advanced cervical cancer treated with curative chemoradiotherapy between 1999 and 2014 at our hospital.

\section{RESULTS}

The median follow-up period was 37.5 months (range: 5.6-186 months). All patients received both external beam radiation therapy (EBRT) and intracavitary brachytherapy. EBRT was delivered with conventional 2-dimensional radiotherapy or 3-dimensional conformal radiotherapy (3DCRT). Eighty-seven percent of patients received cisplatinum-based chemotherapy during EBRT. Total or nearly total remission was achieved in $72 \%$ of patients. With a median follow-up duration of 37.5 months, $29 \%$ of patients died, $13 \%$ of patients had local-regional recurrence, and $25 \%$ of patients had distant metastasis. The 2-, 5 -, and 10-year overall survival rates were $76 \%, 62 \%$, and $47 \%$, respectively, and the progression-free survival rates were $68 \%, 62 \%$, and $58 \%$, respectively. We evaluated prognostic factors for overall survival and progression-free survival. The most important prognostic factor was the radiotherapy technique. The survival curves were estimated by the Kaplan-Meier method, and differences were assessed using the log-rank test; a p-value $<0.05$ was considered significant.

\section{CONCLUSION}

Chemoradiotherapy is an effective and tolerable treatment method for patients with cervical cancer. These patients treated with 3DCRT have a better overall survival.

Keywords: Prognostic factors; Radiotherapy; Radiotherapy technique; Cervical cancer.

Copyright $\odot$ 2018, Turkish Society for Radiation Oncology

\section{Introduction}

Cervical cancer is the 4th most commonly diagnosed cancer in women worldwide and one of the best-known malignancies.[1] The accepted etiological factors are early first intercourse, multiple partners, high parity, and infections.[2-3] Case-control studies and prevalence surveys have shown that human papilloma virus 
DNA can be detected in patients with cervical cancer in $90 \%-100 \%$ of cases.[4]

While the standard treatment for patients with LACC (stages IB2-IVA ) is concomitant chemoradiotherapy, radical hysterectomy is used as the primary therapy for patients with early-stage carcinoma (stages IA-IB1) of the cervix.[5,6] Today, the 2DRT technique has been replaced by the 3DCRT technique and intensity-modulated radiotherapy (IMRT), thus aiming to reduce the complication rates.

Here, we evaluated the treatment results and prognostic factors in patients treated with chemoradiotherapy and compared 2 different treatment techniques .

\section{Materials and Methods}

We retrospectively reviewed the records from a single institution of 150 patients with LACC treated with curative chemoradiotherapy between 1999 and 2014. Pretreatment evaluation comprising gynecological examination, magnetic resonance imaging, computed tomography (CT), and/or 18F-fluorodeoxyglucose positron emission tomography (beginning in 2008) was performed for all patients for staging. All patients received pelvic external beam radiation therapy (EBRT), followed by intracavitary brachytherapy. Ten patients with metastatic paraaortic lymph nodes were irradiated with extended field. Pelvic EBRT was delivered at a total dose of 45-50.4 Gy (median: $50.4 \mathrm{~Gy}$ ) in 1.8-Gy fraction doses using 18-25 MV X-rays. However, extended-field EBRT was delivered at a total dose of $45 \mathrm{~Gy}$ in 1.8-Gy fraction doses.

Until June 2009, 2DRT with a 4-field box technique [anterior-posterior (AP)-posterior-anterior (PA) and 2 lateral] was used; subsequently, 3DCRT (AP-PA and 2 lateral plus 3 or 4 segments) was performed. For planning 2DRT, X-Ray (conventional) simulator was used, and the edges of fields were determined with standardized simulator planning guided by bony landmarks for the pelvic irradiation of primary cervical carcinoma (the superior border of the AP-PA field at the inferior edge of $\mathrm{L} 4$, the inferior border at the inferior edge of the ischium, the lateral borders placed $2 \mathrm{~cm}$ outside of the bony pelvis rim, the anterior border of the lateral field over the anterior edge of the pubic symphysis, and the posterior border at the S2-S3 interspace). For para-aortic nodes, the superior border of the AP-PA field was at the T12-L1 interspace, and the width of the AP-PA field was approximately $10 \mathrm{~cm}$ (encompass tips of the transverse processes).

For planning 3DCRT, CT simulation images of the patients were taken (adjacent axial slice spacing, 2.5 mm; GE-Lightspeed $64^{\circledR}$ computed tomography simulator; GE, Fairfield, USA). The target volumes and critical normal tissues (bowel, bladder, and rectum) were outlined on each CT slice.

Following EBRT, all patients underwent "Nucletron Microselectron IR-192" high-dose-rate brachytherapy, which was applied at a total dose of 28-30 Gy in 6-7Gy fraction doses. Concurrent weekly cisplatin at 35-40 $\mathrm{mg} / \mathrm{m}^{2}$ was administered intravenously during EBRT.

The survival curves were estimated by the KaplanMeier method, and differences were assessed using the log-rank test; p-values $<0.05$ were considered significant. Prognostic factors studied were age, tumor size $(>4 \mathrm{~cm}, \leq 4 \mathrm{~cm}$ ), stage, vaginal extension, pelvic wall

\begin{tabular}{|c|c|c|c|c|c|c|}
\hline & $\begin{array}{l}\text { acter } \\
\text { ique }\end{array}$ & $\begin{array}{l}\text { ristics a } \\
\text { es }\end{array}$ & rding & to $2 \mathrm{C}$ & T and \\
\hline & & \multicolumn{2}{|c|}{ 2DRT } & \multicolumn{2}{|c|}{ 3DCRT } & \multirow[t]{2}{*}{ P value } \\
\hline & & & (\%) & $\mathbf{n}$ & (\%) & \\
\hline \multicolumn{2}{|c|}{ Patient number } & & $2(35)$ & 98 & (65) & \\
\hline \multicolumn{2}{|c|}{ Mean age } & \multicolumn{2}{|c|}{56.5} & \multicolumn{2}{|c|}{54} & 0.2 \\
\hline \multicolumn{2}{|c|}{ FIGO } & & & & & 0.08 \\
\hline \multicolumn{2}{|l|}{$\mathrm{lb}$} & 2 & (3.8) & 7 & $(7.1)$ & \\
\hline \multicolumn{2}{|l|}{ Ila } & 0 & $(0)$ & 10 & $(10.2)$ & \\
\hline \multicolumn{2}{|l|}{ Ilb } & 33 & $(63.5)$ & 64 & $(65.3)$ & \\
\hline \multicolumn{2}{|l|}{ Illa } & 3 & $(5.8)$ & 2 & $(2.0)$ & \\
\hline \multicolumn{2}{|l|}{ Illb } & 9 & $(17.3)$ & 9 & (9.2) & \\
\hline \multicolumn{2}{|l|}{ IVa } & 5 & (9.6) & 6 & (6.1) & \\
\hline \multicolumn{4}{|c|}{ Lymphadenopathy } & & & 0.1 \\
\hline \multicolumn{2}{|c|}{ Yes } & 5 & $(12.8)$ & 23 & $(24.0)$ & \\
\hline \multicolumn{2}{|l|}{ No } & 34 & $(87.2)$ & 73 & $(76.0)$ & \\
\hline \multicolumn{2}{|c|}{ Histologic type } & & & & & 0.7 \\
\hline \multicolumn{2}{|c|}{ Squamous } & 42 & $(80.8)$ & 86 & $(87.8)$ & \\
\hline \multicolumn{2}{|c|}{ Adenocarcinoma } & 3 & $(5.8)$ & 4 & $(4.1)$ & \\
\hline \multicolumn{2}{|c|}{ Adenosquamous } & 6 & $(11.5)$ & 7 & (7.1) & \\
\hline \multicolumn{2}{|c|}{ Other } & 1 & $(1.9)$ & 1 & $(1.0)$ & \\
\hline \multicolumn{2}{|c|}{ Tumor size } & & & & & 0.5 \\
\hline \multicolumn{2}{|c|}{$\leq 4 \mathrm{~cm}$} & 22 & $(43.1)$ & 46 & (48.9) & \\
\hline \multicolumn{2}{|l|}{$>4 \mathrm{~cm}$} & 29 & $(56.9)$ & 48 & $(51.1)$ & \\
\hline \multicolumn{2}{|c|}{ Vaginal extension } & & & & & 0.001 \\
\hline \multicolumn{2}{|c|}{ Yes } & 33 & $(63.5)$ & 27 & $(27.6)$ & \\
\hline \multicolumn{2}{|l|}{ No } & 19 & (36.5) & 71 & (72.4) & \\
\hline Paramet & al extension & & & & & 0.006 \\
\hline Yes & & 49 & $(94.2)$ & 75 & (76.5) & \\
\hline No & & 3 & $(5.8)$ & 23 & $(23.5)$ & \\
\hline Pelvic wa & involvement & & & & & 0.006 \\
\hline Yes & & 11 & $(21.2)$ & 6 & $(6.1)$ & \\
\hline No & & 41 & $(78.8)$ & 92 & (93.9) & \\
\hline Extende & field & & & & & 0.7 \\
\hline (Pelvic+F & raaortic RT) & 4 & (7.7) & 6 & (6.1) & \\
\hline
\end{tabular}

2DRT: conventional 2-dimensional radiotherapy, 3DCRT: 3-dimensional conformal radiotherapy. 


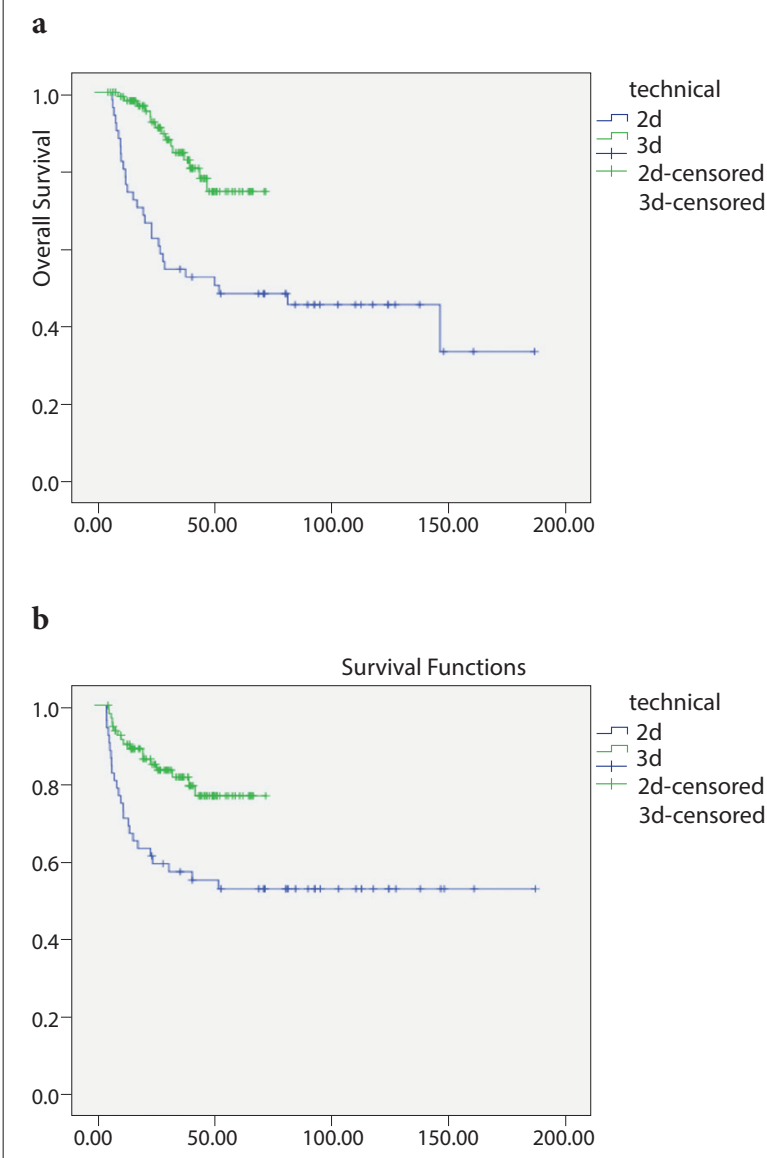

Fig. 1. Kaplan-Meier survival curves for (a) overall survival and (b) progression-free survival.

involvement, parametrial extension, and radiotherapy technique (2DRT or 3DCRT). The level of significance was set at $\mathrm{p}<0.05$. In addition, "stepwise cox regression analysis" was performed.

\section{Results}

The median age at diagnosis was 55 years (range: 23-91 years). According to the International Federation of Gynecology and Obstetrics staging system, $6 \%$ of patients were in stage I, $71 \%$ were in stage II, $16 \%$ were in stage III, and $7 \%$ were in stage IV. Histopathologically, $85 \%$ of the patients had squamous cell carcinoma. Mean clinical and radiological tumor diameter was $4.9 \mathrm{~cm}$. Vaginal extension was seen in 60 patients (40\%): $2 / 3$ upper in $82 \%$ and $1 / 3$ lower part of the vagina in $18 \%$ of the 60 patients. Sixty-nine patients (46\%) underwent lymph node dissection, and 35 patients (23\%) had pathological lymph node metastasis. Ten patients had para-aortic lymph node metastasis by radiology or pathology.
Table 2 Survival outcomes of patients receiving 2DRT and 3DCRT

\begin{tabular}{lcc} 
& 2DRT & 3DCRT \\
\hline 2 year OS-DFS rates & $56 \%-58 \%$ & $85 \%-82 \%$ \\
5 year OS-DFS rates & $50 \%-53 \%$ & $76 \%-77 \%$ \\
10 year OS-DFS rates & $47 \%-53 \%$ & - \\
\hline
\end{tabular}

Whereas 2DRT was performed in 52 patients (35\%), 3DCRT was performed in 98 patients (65\%). Table 1 shows the characteristics of the patients according to the technique. All patients completed EBRT and brachytherapy as planned. The mean total equivalent dose in 2 Gy/fraction dose was calculated as 89.2 Gy (range: 80-91.7 Gy). The para-aortic fields were also treated in 10 patients due to positive para-aortic lymph nodes by radiology or pathology.

In total, 130 patients $(87 \%)$ received cisplatin-based concomitant chemotherapy $\left(35-40 \mathrm{mg} / \mathrm{m}^{2}\right.$ once per week), whereas 10 patients did not receive concomitant chemotherapy because of extended field for the external irradiation of para-aortic lymph nodes, it was not evident whether 10 patients received chemotherapy.

With a median follow-up duration of 37.5 months (range: 5.6-186 months), 99 patients (66\%) had no evidence of disease at the last follow-up. During follow-up, 43 patients (29\%) had recurrence by imaging and clinical examination, 19 patients had loco-regional relapse, 37 patients had distant metastases, and 13 patients had both loco-regional and distant metastases. It was detected that the loco-regional relapse rate of 3DCRT was lower than that of 2DRT ( $2 \%$ and $33 \%$, respectively) $(\mathrm{p}=0.001)$. Distant metastasis rates of 3DCRT and 2DRT were $19 \%$ and $38 \%$, respectively $(0.01)$.

The 2-, 5-, and 10-year overall survival (OS) and DFS rates were $76 \%, 62 \%$, and $47 \%$ and $68 \%, 62 \%$, and $58 \%$, respectively.

Age $(\mathrm{p}=0.01)$, stage $(\mathrm{p}=0.001)$, vaginal extension $(\mathrm{p}=0.02)$, pelvic wall involvement $(\mathrm{p}=0.001)$, and radiotherapy technique $(p<0.001)$ were found to be significant prognostic factors in terms of OS.

The radiotherapy technique was found to be the only significant prognostic factor for DFS $(\mathrm{p}<0.001)$. The radiotherapy technique was the most important factor according to stepwise cox regression analysis.

Survival rates were superior in patients receiving 3DCRT (Table 2). Figure 1 shows the survival curves of 2DRT and 3DCRT.

In the follow-up period, after the completion of radiotherapy, rectovaginal fistula and small bowel adhesion were observed in 2 patients, both of whom were 
treated with 3DCRT. Serious side effects were not observed in the other patients during or after radiotherapy.

\section{Discussion}

The standard treatment for patients with early-stage cervical cancer is surgery. Chemoradiotherapy has an essential role in curative treatment in patients with LACC. After 5 randomized trials published between 1999 and 2000, the survival advantage of curative chemoradiotherapy has been proven, and it has been accepted as the standard treatment for LACC.[5-9] Based on a metaanalysis, a potential absolute OS and DFS benefit of $12 \%$ and $16 \%$, respectively, has been attributed to the use of chemoradiotherapy.[10] Cohrane's meta-analysis analyzed and compared the results of 13 studies on chemoradiotherapy versus radiotherapy.[11] The meta-analysis showed a $6 \%$ improvement in the 5-year survival with chemoradiotherapy. Chemoradiotherapy was also found to reduce progression and improve DFS. Five retrospective studies have demonstrated that the 5-year OS with chemoradiotherapy ranges from $55 \%$ to $73 \%$ in patients with LACC.[12-16] In our series, the 5-year OS of 150 patients was $62 \%$. According to the techniques, the 5 -year OS of 3DCRT and 2DRT were $76 \%$ and $50 \%$, respectively. In our study, despite the high rate of patients with stage IV and para-aortic nodal metastases and the fact that $13 \%$ of our patients did not receive concurrent chemotherapy, our results are consistent with those reported in the literature.

The benefit of brachytherapy in terms of survival and local control has been reported by Coia et al.[17] In their study, the use of brachytherapy and the number of intracavitary insertions were significantly associated with survival. At 4 years, local failure was significantly reduced (29\% versus $17 \%$ ) with 2 or more intracavitary applications and the survival rate was improved $(60 \%$ versus $73 \%$ ). In our study, all patients received brachytherapy.

Previous studies have confirmed age, performance status, tumor diameter, and lymph node status as prognostic factors of the progression-free rate for patients with LACC. $[18,19]$ All these factors in addition to clinical stage and bilateral parametrial or bilateral pelvic wall extension were significant for survival. Pelvic nodal status and tumor diameter have been reported to be significant independent prognostic factors for survival and recurrence. In our study, age, stage, vaginal extension, pelvic wall involvement, and radiotherapy technique were found to be significant prognostic factors in terms of OS.
To the best of our knowledge, our study is one of the few studies in the literature that has compared 3DCRT and 2DRT techniques regarding survival in the longterm follow-up period. In a study, the 5-year survival rate for 2DRT and 3DCRT was found to be significantly different $(73.0 \%$ and $82.3 \%$, respectively). Accompanying comorbidities of these patients were also examined, and patients with cervical cancer with more comorbidities were found to have poorer survival rates.[20] In our study, the survival results were better in the patients receiving 3DCRT, as expected. However, a limitation of our study was the heterogeneity between the 2 groups.

In 2013, a study compared conformal and conventional radiotherapy techniques in 5 patients dosimetrically.[21] Dose homogeneity and doses of the organs at risk (rectum, bladder, and small bowel) were not significantly improved. However, 3DCRT provided a significantly better target coverage. In addition, the use of CT simulation allowed superior visualization of the pelvic lymph nodes and reduced the chances of geographical miss. Therefore, they reported that it might be better in local control and survival. Gulia et al. performed a dosimetric comparison between the conventional 4-field based on bony landmarks and the target volume delineated on CT in 50 patients.[22] They showed that DFS is lower in patients with inadequate target volume coverage. They recommended the routine use of CT-based planning for the 4-field technique.

In our study, the radiotherapy technique was the most important prognostic factor. Patients receiving 3DCRT had superior survival rates and treatment responses. The primary reason for this was that the error risks arising from a potential geographic miss or individual anatomical variations were reduced because the target volume and critical normal tissues were determined based on CT-simulation images. The other reason was that 3DCRT demonstrated a better coverage and dose homogeneity inside the CTV because of the added segments to lateral fields.

Throughout pelvic radiotherapy or after the completion of treatment, genitourinary or gastrointestinal side effects have been shown.[23,24] In our study, severe complications were observed in only 2 patients. Nutrition education was important to reduce gastrointestinal complications. Furthermore, prior abdominal and pelvic surgery was also a high-risk factor for toxicities; this was not performed in our patients. It was also important in reducing the risk of developing complications. Chemoradiotherapy was well tolerated by our patients.

Modern technologies in radiotherapy delivery, such as IMRT, allow greater sparing of normal tissues and 
provide highly conformal dose distributions. Although advantages of EBRT in patients with LACC treated with IMRT have been shown in terms of survival and side effects, it may have disadvantages, such as motion or filling of organs, and inhomogeneity within target volumes may affect local control.[25-28]

Although the application of IMRT in patients with definitive cervical cancer is not yet a standard approach, prospective clinical studies are needed to evaluate the comparative efficacy of IMRT and conventional or 3DCRT techniques.

\section{Conclusion}

In stages IB-IV cervical cancer, chemoradiotherapy is effective and acceptable with regard to local control and survival advantage, and a reasonable rate of complications is observed. Furthermore, the conformal radiotherapy technique has been shown to be superior to the conventional radiotherapy technique. Further studies are needed to define the rate of toxicities and factors affecting the management of patients with LACC.

Peer-review: Externally peer-reviewed.

Conflict of Interest: No potential conflict of interest relevant to this article was reported.

Authorship contributions: Concept - B.Ş.Ö.; Design B.Ş.Ö., G.M.A.; Supervision - B.Ş.Ö., G.M.A., M.G.; Materials - B.Ş.Ö., G.M.A., M.N.Y., T.B.; Data collection \&/or processing - B.Ş.Ö.; Analysis and/or interpretation - B.Ş.Ö., G.M.A.; Literature search - B.Ş.Ö., G.M.A.; Writing - B.Ş.Ö.; Critical review - B.Ş.Ö., G.M.A., A.F.K.

\section{References}

1. Torre LA, Bray F, Siegel RL, Ferlay J, Lortet-Tieulent J, Jemal A. Global cancer statistics, 2012. CA Cancer J Clin 2015;65(2):87-108. [CrossRef]

2. Christopherson WM, Parker JE. Relation of cervical cancer to early marriage and childbearing. $\mathrm{N}$ Engl J Med 1965;273:235-9. [CrossRef]

3. Keighley E. Carcinoma of the cervix among prostitutes in a women's prison. Br J Vener Dis 1968;44(3):254-5.

4. Bosch FX, Lorincz A, Muñoz N, Meijer CJ, Shah KV. The causal relation between human papillomavirus and cervical cancer. J Clin Pathol 2002;55(4):244-65. [CrossRef]

5. Rose PG, Bundy BN, Watkins EB, Thigpen JT, Deppe G, Maiman MA, et al. Concurrent cisplatin-based radiotherapy and chemotherapy for locally advanced cervical cancer. N Engl J Med 1999;340(15):1144-53. [CrossRef]

6. Peters WA 3rd, Liu PY, Barrett RJ 2nd, Stock RJ, Monk
BJ, Berek JS, et al. Concurrent chemotherapy and pelvic radiation therapy compared with pelvic radiation therapy alone as adjuvant therapy after radical surgery in high-risk early-stage cancer of the cervix. J Clin Oncol 2000;18(8):1606-13. [CrossRef]

7. Morris M, Eifel PJ, Lu J, Grigsby PW, Levenback C, Stevens RE, et al. Pelvic radiation with concurrent chemotherapy compared with pelvic and para-aortic radiation for high-risk cervical cancer. $\mathrm{N}$ Engl J Med 1999;340(15):1137-43. [CrossRef]

8. Keys HM, Bundy BN, Stehman FB, Muderspach LI, Chafe WE, Suggs CL 3rd, et al. Cisplatin, radiation, and adjuvant hysterectomy compared with radiation and adjuvant hysterectomy for bulky stage IB cervical carcinoma. N Engl J Med 1999;340(15):1154-61. [CrossRef]

9. Whitney CW, Sause W, Bundy BN, Malfetano JH, Hannigan EV, Fowler WC Jr, et al. Randomized comparison of fluorouracil plus cisplatin versus hydroxyurea as an adjunct to radiation therapy in stage IIB-IVA carcinoma of the cervix with negative para-aortic lymph nodes: a Gynecologic Oncology Group and Southwest Oncology Group study. J Clin Oncol 1999;17(5):133948. [CrossRef]

10. Green JA, Kirwan JM, Tierney JF, Symonds P, Fresco L, Collingwood M, et al. Survival and recurrence after concomitant chemotherapy and radiotherapy for cancer of the uterine cervix: a systematic review and metaanalysis. Lancet 2001;358(9284):781-6. [CrossRef]

11. Chemoradiotherapy for Cervical Cancer Meta-analysis Collaboration (CCCMAC). Reducing uncertainties about the effects of chemoradiotherapy for cervical cancer: individual patient data meta-analysis. Cochrane Database Syst Rev 2010;(1):CD008285.

12. Atahan IL, Onal C, Ozyar E, Yiliz F, Selek U, Kose F. Long-term outcome and prognostic factors in patients with cervical carcinoma: a retrospective study. Int J Gynecol Cancer 2007;17(4):833-42. [CrossRef]

13. Özsaran Z, Yalman D, Dubova S, Akagündüz O, Aras A, Haydaroglu A. Lokal ileri evre serviks kanserinde radyoterapi sonuçları: Ege Üniversitesi deneyimi. Türk Jinekolojik Onkoloji Dergisi 2005;8;5-13.

14. Teh J, Yap SP, Tham I, Sethi VK, Chua EJ, Yeo R, et al. Concurrent chemoradiotherapy incorporating high-dose rate brachytherapy for locally advanced cervical carcinoma: survival outcomes, patterns of failure, and prognostic factors. Int J Gynecol Cancer 2010;20(3):428-33. [CrossRef]

15. Parker K, Gallop-Evans E, Hanna L, Adams M. Five years' experience treating locally advanced cervical cancer with concurrent chemoradiotherapy and high-doserate brachytherapy: results from a single institution. Int J Radiat Oncol Biol Phys 2009;74(1):140-6. [CrossRef]

16. Lim A, Sia S. Outcomes of chemoradiotherapy in cervical cancer-the Western Australian experience. Int J Ra- 
diat Oncol Biol Phys 2012;82(4):1431-8. [CrossRef]

17. Coia L, Won M, Lanciano R, Marcial VA, Martz K, Hanks G. The Patterns of Care Outcome Study for cancer of the uterine cervix. Results of the Second National Practice Survey. Cancer 1990;66(12):2451-6. [CrossRef]

18. Stehman FB, Bundy BN, DiSaia PJ, Keys HM, Larson JE, Fowler WC. Carcinoma of the cervix treated with radiation therapy. I. A multi-variate analysis of prognostic variables in the Gynecologic Oncology Group. Cancer 1991;67(11):2776-85. [CrossRef]

19. Kodaira T, Fuwa N, Kamata M, Furutani K, Kuzuya K, Ogawa K, et al. Clinical assessment by MRI for patients with stage II cervical carcinoma treated by radiation alone in multicenter analysis: are all patients with stage II disease suitable candidates for chemoradiotherapy? Int J Radiat Oncol Biol Phys 2002;52(3):627-36. [CrossRef]

20. Hsieh CH, Tsai SJ, Chiou WY, Lee MS, Lin HY, Hung SK. Better survival with three-dimensional conformal radiotherapy than with conventional radiotherapy for cervical cancer: a population-based study. ISRN Oncol 2013;2013:729819. [CrossRef]

21. Goswami J, Patra NB, Sarkar B, Basu A, Pal S. Dosimetric comparison between conventional and conformal radiotherapy for carcinoma cervix: Are we treating the right volumes? South Asian J Cancer 2013;2(3):128-31.

22. Gulia A, Patel FD, Santam C, Bhavana R, Reena K, Sharma SC. Clinical significance of geographic miss when using conventional four field radiotherapy technique in treatment of locally advanced carcinoma cervix. Indian
J Cancer 2016;53(1):80-5. [CrossRef]

23. Pedersen D, Bentzen SM, Overgaard J. Early and late radiotherapeutic morbidity in 442 consecutive patients with locally advanced carcinoma of the uterine cervix. Int J Radiat Oncol Biol Phys 1994;29(5):941-52. [CrossRef] 24. Bohr Mordhorst L, Karlsson L, Bärmark B, Sorbe B. Combined external and intracavitary irradiation in treatment of advanced cervical carcinomas: predictive factors for treatment outcome and early and late radiation reactions. Int J Gynecol Cancer 2014;24(7):126875. [CrossRef]

25. Chen CC, Lin JC, Jan JS, Ho SC, Wang L. Definitive intensity-modulated radiation therapy with concurrent chemotherapy for patients with locally advanced cervical cancer. Gynecol Oncol 2011;122(1):9-13. [CrossRef]

26. Jadon R, Pembroke CA, Hanna CL, Palaniappan N, Evans $\mathrm{M}$, Cleves $\mathrm{AE}$, et al. A systematic review of organ motion and image-guided strategies in external beam radiotherapy for cervical cancer. Clin Oncol (R Coll Radiol) 2014;26(4):185-96. [CrossRef]

27. Roeske JC, Bonta D, Mell LK, Lujan AE, Mundt AJ. A dosimetric analysis of acute gastrointestinal toxicity in women receiving intensity-modulated whole-pelvic radiation therapy. Radiother Oncol 2003;69(2):201-7.

28. Hasselle MD, Rose BS, Kochanski JD, Nath SK, Bafana $\mathrm{R}$, Yashar CM, et al. Clinical outcomes of intensitymodulated pelvic radiation therapy for carcinoma of the cervix. Int J Radiat Oncol Biol Phys 2011;80(5):143645. [CrossRef] 